\title{
Inbreeding depression in dioecious populations of the plant Mercurialis annua: comparisons between outcrossed progeny and the progeny of self-fertilized feminized males
}

\author{
SM Eppley ${ }^{1}$ and JR Pannell \\ Department of Plant Sciences, University of Oxford, Oxford, UK
}

\begin{abstract}
Inbreeding depression is a key factor in the maintenance of separate sexes in plants through selection for the avoidance of self-fertilization. However, very little is known about the levels of inbreeding depression in dioecious species, obviously because it is difficult to self-fertilize males or females. We overcame this problem by clonally propagating males from lineages in a dioecious metapopulation of the European annual plant Mercurialis annua, feminizing some of them and crossing the feminized with the unfeminized clones. Using this method, we compared the fitness of selfed vs outcrossed
\end{abstract}

progeny under field conditions in Spain, where this species grows naturally. Multiplicative inbreeding depression (based on seed germination, early and late survival, seed mass and pollen viability) ranged from -0.69 to 0.82 , with a mean close to zero. We consider possible explanations for both the low mean and high variance in inbreeding depression in $M$. annua, and we discuss the implications of our results for the maintenance of dioecy over hermaphroditism.

Heredity (2009) 102, 600-608; doi:10.1038/hdy.2009.21; published online 18 March 2009

Keywords: sexual system; dioecy; inbreeding depression; Mercurialis annua; outbreeding depression; outcrossing

\section{Introduction}

Inbreeding depression, the reduction in fitness of inbred progeny relative to their outbred half-sibs, has implications for several areas of evolutionary biology, including inbreeding avoidance (Lande and Schemske, 1985; Charlesworth and Charlesworth, 1990; Charlesworth et al., 1990; Morgan, 2001), the evolution and maintenance of sexual systems (Darwin, 1877; Charlesworth and Charlesworth, 1978), the establishment of polyploids (Rausch and Morgan, 2005) and extinction rates of small populations (Lande, 1988; Frankham, 1995). Inbreeding depression is considered to be the major force countering the evolution of self-fertilization in angiosperms (Darwin, 1876; Fisher, 1949; Lande and Schemske, 1985; Lloyd and Schoen, 1992; Charlesworth and Charlesworth, 1998). In simple models, selfing should only be able to evolve in an outcrossing hermaphroditic population when inbreeding depression $(\delta)$ is low; if $\delta$ is high then the population is protected against the invasion of selfing variants (reviewed in Goodwillie et al., 2005). Similarly, the successful invasion of partially selfing hermaphrodites into dioecious populations will depend on the magnitude of the product of the selfing rate, $s$, and $\delta$

Correspondence: Dr JR Pannell, Department of Plant Sciences, University of Oxford, South Parks Road, Oxford OX1 3RB, UK.

E-mail: john.pannell@plants.ox.ac.uk

${ }^{1}$ Current address: Department of Biology, Portland State University, PO Box 751, Portland, OR 97207-0751, USA.

Received 17 September 2008; revised 13 November 2008; accepted 23 December 2008; published online 18 March 2009
(Lloyd, 1975, 1976; Charlesworth and Charlesworth, 1978; Charlesworth and Charlesworth, 1981; see also Wolf and Takebayashi, 2004 and Discussion).

Inbreeding depression is expected to vary with historic levels of outcrossing because inbreeding can lead to the purging of deleterious recessive alleles that cause inbreeding depression (Lande and Schemske, 1985; Charlesworth and Charlesworth, 1987; Goodwillie et al., 2005). Some empirical evidence supports this expectation. For example, in plant species that entirely outcross, inbreeding depression is generally found to be high (mean $\delta=0.53$ ) compared with primarily selfing species $(\delta=0.23$; Husband and Schemske, 1996). In some gynodioecious species, inbreeding depression is sufficiently high to explain the maintenance of females (Kohn and Biardi, 1995; Schultz and Ganders, 1996; Sakai et al., 1997; Thompson et al., 2004; Medrano et al., 2005; but see Ashman, 1992; Eckhart, 1992; Koelewijn and van Damme, 2005). However, for dioecious plant species, which are obligate outcrossers, there are currently estimates of inbreeding depression only in two species, one showing high levels (Dorken et al., 2002) and the other showing low levels (Bram, 2002). It is thus difficult to make generalizations about the level of inbreeding depression in dioecious species.

Here, we report the levels of inbreeding depression across a dioecious metapopulation of the plant Mercurialis annua, a wind-pollinated annual herb that is widespread in Europe. M. annua displays monoecy, dioecy and androdioecy (the coexistence of males with hermaphrodites) in different parts of its range (Durand, 
1963; Durand and Durand, 1992; reviewed in Pannell et al., 2004, 2008), and the distribution of these sexual systems, as well as patterns of sex allocation within each system, is consistent with a metapopulation model (Durand, 1963; Pannell, 1997b,c; Obbard et al., 2006b; Eppley and Pannell, 2007b). In this study, we sampled lineages from a dioecious metapopulation in Catalonia, Spain, using a novel procedure to create selfed progeny. This procedure involved the feminization of individuals cloned from males through the exogenous application of phytohormones, followed by the crossing of the feminized male with its unfeminized male clone (see Durand and Durand, 1991). We created selfed and outcrossed progeny within the same lineages, and we replicated lineages among populations rather than within populations to increase the breadth of our study across the metapopulation. We planted selfed and outcrossed progeny into the field in Spain under natural conditions and calculated cumulative inbreeding depression for each lineage. We measured levels of inbreeding depression under natural field conditions with both intra- and inter-specific competition, including competition among inbred and outbred lines.

\section{Materials and methods}

\section{Study populations}

M. апnиа (Euphorbiaceae) is a wind-pollinated annual herb that is common across western Europe and around the Mediterranean Basin. It shows a striking variation in its sexual system, a range of ploidy levels and an apparent metapopulation structure (Durand, 1963; Durand and Durand, 1992; Pannell, 1997b,c; Pannell et al., 2004, 2008; Obbard et al., 2006b; Eppley and Pannell, $2007 \mathrm{~b}$ ). For this study, we sampled dioecious lineages from a metapopulation in Catalonia, Spain. To obtain lineages, we sampled populations between 1999 and 2001 from disturbed anthropogenic habitat, along roadsides within $110 \mathrm{~km}$ from one another and within $18 \mathrm{~km}$ of the coast. Seeds were collected from 20 populations (collection reference numbers are given in parentheses): (1) Avinyonet del Penedès (no. 0051a), (2) Barcelona (location 1) (no. 0001), (3) Barcelona (location 2) (no. 0048), (4) north of Sant Boi de Llobregat (no. 0047), (5) Viladecans (no. 0046), (6) Castelldefels (no. 0044), (7) Garraf (no. 0043), (8) east of Sitges (no. 0042), (9) Sitges (no. 0041), (10) Canyelles (no. 0035), (11) Vilafranca del Penedés (no. 0036), (12) Vilanova i la Geltru (no. 0033), (13) Cubelles (no. 0032), (14) north of El Vendrell (no. 0038), (15) Coma-Ruga (no. 0027), (16) Torredembarra (no. 0026), (17) Altafulla (no. 0025), (18) Tarragona (no. 0024), (19) Reus (no. 0018) and (20) Mas Busca (no. 714). Further details about site localities can be obtained from the authors upon request.

\section{Experimental design}

In May 2003, we sowed seeds from two maternal families from each population in pots in a glasshouse in Oxford. When plants were in the flowering stage, we chose a focal male from one of the two maternal families for each population; we outcrossed this focal plant to individuals from the other maternal family from the same population (as described below); we self-fertilized the focal plant; and we compared offspring fitness among crosses to assess inbreeding depression. Thus, our experimental design allowed one lineage per population (based on the focal male), with multiple populations sampled across the dioecious metapopulation.

To produce sufficient plant material to both selffertilize and outcross the focal male, we took cuttings from each focal plant to create three separately potted clonal ramets of each plant. Cuttings were dipped in rooting powder, with the active ingredient 1-naphthaleneacetic acid, to promote root formation. Self-fertilization of male plants is made possible by altering gender expression through the exogenous application of phytohormones (Durand and Durand, 1991). Using hormone spray ( $0.2 \mathrm{~g}$ of 6-benzyl aminopurine into 191 of water) applied twice a day, we feminized a subset of the focal ramets and of one male from an alternate maternal family for each population.

In August 2003, each focal plant was self-fertilized and outcrossed by placing the appropriate plant into a pollen-proof box under natural lighting conditions. For the self-fertilization treatment, two ramets of the focal plant were placed in the same box; one ramet was feminized and the other was not. For the outcrossing treatment, one non-feminized ramet of the focal plant (pollen donor) was placed in a box, with three feminized plants from the alternate maternal family from the same population and three female plants (which did not receive hormone) from the alternate maternal family from the same population. Thus, for both selfed and outcrossed treatments, pollen was produced by individuals that did not receive the hormone spray, and seeds were matured on all selfed individuals and on three plants per population of crossed individuals treated with hormone spray. One limitation of this design, which does not apply to inbreeding depression experiments with hermaphroditic species, is that selfed and outcrossed progenies are matured on different plants. We tested for, but found no significant effect of, maternal plant on the fitness of outcrossed vs selfed progeny (see analysis below).

In addition, seeds were produced by outcrossing on the three females per population that had not received hormone spray, allowing for a control of the hormone treatment among the outcrossed plants. A larger number of out- vs self-crosses were conducted to test the fitness effects of the hormone treatment adequately; however, difficulties in clonal propagation limited replication of the selfing treatment. The hormone treatment had no effect on the progeny fitness measures (see Supplementary information).

When placed in pollen-proof boxes, plants that had received a hormone spray earlier were watered with the hormone solution to maintain their feminization. We checked that the boxes prevented pollen contamination and that females did not self-fertilize by isolating four females and four feminized males in boxes on their own; none of these plants produced seeds. After 8 weeks, the plants were harvested, dried in a drying oven for $48 \mathrm{~h}$ and the seeds separated from the remaining plant tissue. Mortality in the greenhouse, caused primarily by pathogen damage, reduced the final number of populations for which we obtained sufficient numbers of both selfed and outcrossed seeds. However, mortality was not statistically associated with crossing type in boxes $\left(N=108 ; \chi^{2}=0.24 ; P=0.62\right)$, and plant mass, seed mass 
and seed number did not differ significantly between selfed and outcrossed feminized males for crosses in the boxes $(N=35 ;$ d.f. $=1 ; P=0.47, P=0.54$ and $P=0.21$, respectively, using one-way analysis of variance), suggesting that crossing conditions were consistent, as intended. We obtained self- and cross-fertilized seeds from 13 of the original 20 populations; $68.5 \pm 18.9$ (s.e.) seeds were produced per plant for selfed crosses, and $102 \pm 18.1$ (s.e.) seeds were produced per plant for outcrossed crosses. Lineages from populations $3,10,13$, $14,16,18$ and 20 produced insufficient seed to be included in the final analyses.

\section{Inbreeding depression measurements}

In February 2004, 2287 seeds were planted in a greenhouse at the Centro de Investigaciones sobre Desertificación near Valencia, Spain. Individual lineages and crosses were planted into separate trays. For one population $(N=18$ outcrossed seeds and 67 selfed seeds), no seeds of either crossing treatment germinated, and this lineage was dropped from the experiment. In March, the 467 seedlings that had germinated and survived were counted and transferred to the field. Seedlings were at the cotelydon stage, with no leaves emerged. The field site was a patch of abandoned land adjacent to the research centre in which a $M$. annua population occurred. The site was cleared of vegetation and tilled to mimic the natural conditions into which this ruderal species germinates. Seedlings were randomly assigned a location in the field and were planted into 12 rows. To ensure high intraspecific competition, seedlings were planted close together $(1 \mathrm{~cm}$ apart) within rows, and the rows were separated from each other by $1 \mathrm{~cm}$ on one side and $15 \mathrm{~cm}$ on the other. These densities are similar to those observed in natural populations of $M$. annua. The plot was left unweeded for the duration of the experiment. We recorded the relative cover of other species in the plots at the time of harvest and found no difference in the interspecific cover experienced by outcrossed vs selfed plants in the experiment $(N=466$; $\left.\chi^{2}=0.14 ; P=0.71\right)$

In late May, two flowers each were collected from a random subset of the male plants $(N=268)$, and pollen from one anther per flower was preserved in lactophenol-aniline blue on a glass slide for pollen viability analysis (Kearns and Inouye, 1993). This technique is likely to overestimate pollen viability because not all pollen grains that stain well are necessarily capable of germination (Stanley and Linskens, 1974). We assessed the viability of 200 pollen grains per individual plant using a compound microscope. The surviving plants $(N=466)$ were then harvested, dried and weighed. As a few plants were damaged during transport, we obtained the mass for 456 plants. Seeds were removed from female plants and weighed separately. Plant dry mass was recorded as the differences between the total mass of the plants including any seeds and the mass of any seeds removed from that plant.

\section{Analysis}

We used a logit model, following Christensen (1990), to determine the effects of cross-type (a fixed effect) and lineage (a random effect) on whether a seed germinated and survived as a seedling (SAS Institute, 2004); we report results as likelihood ratio $\chi^{2}$ values. Maternal plant (from which the seeds were derived during crossing) was not significant in this or subsequent analyses and was not included in the final analyses. As survival was high in the field, a similar logit model could not be used to analyse the survival of plants in the field due to the violation of model assumptions. To determine how crosstype (a fixed effect), lineage (a random effect) and the interaction between cross-type and lineage influenced our remaining fitness measures, we used mixed-model analysis of variance. Plant mass was log transformed, residuals were normally distributed and variances were homogeneous. There was a significant effect of selfing vs outcrossing on progeny biomass; to examine differences between outcrossed and selfed progeny for each lineage, we used standard errors based on 10000 bootstrap samples (S-Plus software; Insightful Corporation, 2007). As we found no effect of the hormone treatment (see Supplementary information), the outcrossed progeny produced on females and feminized males was included in all of these analyses. However, we also analysed data that excluded progeny produced on females (that is, including only selfed and outcrossed progeny of feminized males) and found negligible differences in our results (not shown).

We calculated the fitness of self-progeny relative to outcrossed progeny for each lineage. Multiplicative fitness for females was calculated for each lineage as the product of proportion germination and early survival, proportion survival and seed mass. Plant dry mass was not used in the calculations as it correlated with seed mass $\left(R^{2}=0.68 ; P<0.0001 ; N=149\right)$. Multiplicative fitness for male function was calculated for each lineage as the product of proportion germination and early survival, proportion survival, plant dry mass and proportion viable pollen. A combined multiplicative fitness for both sexual functions was calculated for each lineage by multiplying the germination rate, early survival, adult survival and the term $S+P$, where $S$ is given by half the seed mass, normalized with respect to seed mass in outcrossed progeny, and $P$ is given by half the proportion viable pollen normalized with respect to proportion viable pollen in the outcrossed progeny. This combined function assumes a 1:1 sex ratio, as observed in wild dioecious $M$. annua populations.

When the fitness of outcrossed progeny exceeded that of selfed progeny, inbreeding depression was calculated as $\delta=1-w_{\mathrm{s}} / w_{\mathrm{o}}$. When the fitness of selfed progeny was greater than that of outcrossed progeny, then inbreeding depression was calculated as $\delta=w_{\mathrm{o}} / w_{\mathrm{s}}-1$ (Ågren and Schemske, 1993; Carr et al., 1997; Mutikainen and Delph, 1998). The mean inbreeding depression for dioecious lineages was calculated from lineage means to weight each lineage equally (Johnston and Schoen, 1994). T-tests were used to determine whether the multiplicative inbreeding depression means differed from zero.

\section{Results}

\section{Early life history}

The proportion of individuals that germinated and survived to be transplanted into the field was relatively low (Table 1) and depended on the combination of crossing treatment and lineage (the interaction between 
Table 1 The number of individuals measured $(n)$, the mean values of fitness traits and one standard error $( \pm$ s.e.) for outcrossed and selfed offspring from dioecious lineages of Mercurialis annua

\begin{tabular}{|c|c|c|c|c|c|c|}
\hline \multirow[t]{2}{*}{ Trait } & \multicolumn{3}{|c|}{ Outcrossed } & \multicolumn{3}{|c|}{ Selfed } \\
\hline & $\mathrm{n}$ & Mean & \pm s.e. & $\mathrm{n}$ & Mean & \pm s.e. \\
\hline Proportion germination and early survival & 1313 & 0.25 & 0.03 & 890 & 0.22 & 0.05 \\
\hline Proportion late survival & 298 & 0.97 & 0.01 & 168 & 0.97 & 0.02 \\
\hline Plant dry mass (g) & 288 & 0.26 & 0.01 & 158 & 0.36 & 0.03 \\
\hline Proportion viable pollen & 175 & 0.42 & 0.03 & 93 & 0.40 & 0.07 \\
\hline Seed mass (g) & 84 & 0.025 & 0.004 & 51 & 0.038 & 0.007 \\
\hline
\end{tabular}

Larger sample sizes for outcrossed versus selfed offspring reflect the experimental design (see text).

Table 2 A logit analysis was used to determine the effects of cross-type (outcrossed vs self-fertilization, a fixed effect), lineage (a random effect), and the interaction between cross-type and lineage on whether a seed germinated and the seedling survived in dioecious lineages of Mercurialis annua

\begin{tabular}{|c|c|c|c|c|}
\hline Trait & Cross-type & Lineage & Lineage $\times$ cross-type & Error \\
\hline Proportion germination and early survival & $\begin{array}{c}\text { d.f. }=1 \\
\chi^{2}=1.89\end{array}$ & $\begin{array}{c}\text { d.f. }=12 \\
\chi^{2}=45.0^{* * *}\end{array}$ & $\begin{array}{c}\text { d.f. }=12 \\
\chi^{2}=69.4^{* * *}\end{array}$ & \\
\hline Proportion late survival & $\begin{array}{c}\text { d.f. }=1 \\
M S=0.005 \\
F=0.50\end{array}$ & $\begin{array}{c}\text { d.f. }=12 \\
M S=0.005 \\
F=0.54\end{array}$ & $\begin{array}{c}\text { d.f. }=12 \\
\mathrm{MS}=0.009 \\
\mathrm{~F}=0.72\end{array}$ & $\begin{array}{c}\text { d.f. }=22 \\
\mathrm{MS}=0.01\end{array}$ \\
\hline Plant mass & $\begin{array}{c}\text { d.f. }=1 \\
\mathrm{MS}=0.29 \\
\mathrm{~F}=4.23^{*}\end{array}$ & $\begin{array}{c}\text { d.f. }=12 \\
M S=0.02 \\
F=0.59\end{array}$ & $\begin{array}{c}\text { d.f. }=12 \\
M S=0.04 \\
F=0.38\end{array}$ & $\begin{array}{c}\text { d.f. }=419 \\
\text { MS }=0.10\end{array}$ \\
\hline Proportion pollen viability & $\begin{array}{c}\text { d.f. }=1 \\
\mathrm{MS}=0.005 \\
\mathrm{~F}=0.05\end{array}$ & $\begin{array}{c}\text { d.f. }=11 \\
M S=0.10 \\
F=0.87\end{array}$ & $\begin{array}{c}\text { d.f. }=11 \\
M S=0.11 \\
F=1.16\end{array}$ & $\begin{array}{l}\text { d.f. }=226 \\
M S=0.10\end{array}$ \\
\hline Seed mass & $\begin{array}{c}\text { d.f. }=1 \\
M S=0.005 \\
F=1.16\end{array}$ & $\begin{array}{c}\text { d.f. }=10 \\
\mathrm{MS}=0.004 \\
\mathrm{~F}=0.75\end{array}$ & $\begin{array}{c}\text { d.f. }=10 \\
\text { MS }=0.005 \\
F=3.41^{* * *}\end{array}$ & $\begin{array}{c}\text { d.f. }=114 \\
M S=0.001\end{array}$ \\
\hline
\end{tabular}

Abbreviation: ANOVA, analysis of variance.

ANOVAs were used to determine the effect of cross-type, lineage and the interaction between these factors on multiple fitness measures. Statistically significant values are indicated in bold.

${ }^{*} P<0.05 ;{ }^{* *} P<0.01 ;{ }^{* * *} P<0.001$.

lineage and cross-type was significant; Table 2). Lineagelevel variation in germination and establishment was also reflected in the range of estimated inbreeding depression for this trait $(-0.97$ to 0.94 ; mean $\delta=0.19 \pm 0.16$ ), and in the number of lineages with inbreeding depression both above and below zero, showing significant differences between selfed and outcrossed progeny (Figure 1). Note that the majority of lineages (as represented by one lineage per population, according to the experimental design) showed an inbreeding depression exceeding zero.

\section{Late life history}

Survival of plants in the field was quite high (Table 1), and inbreeding depression was low for this trait $(-0.10$ to 0.25 ; mean $\delta=0.02 \pm 0.03$ ), with the majority of lineages showing an inbreeding depression close to zero (Figure 1). The field conditions created extremely large differences in plant size, with many plants completely dwarfed by their neighbours.

Plant dry mass was significantly affected by cross-type (Tables 1 and 2). Surprisingly, the dry mass of selffertilized progeny was greater than the dry mass of outcrossed progeny. Inbreeding depression for plant dry mass was primarily negative (ranging from -0.58 to 0.25 ; mean $\delta=-0.24 \pm 0.07$; Figure 2 ), with 8 out of 10 lineages showing a negative inbreeding depression.
Pollen viability was fairly low overall, but did not differ significantly between cross-types (Tables 1 and 2). Variation in inbreeding depression ranged from -0.49 to 0.83 for pollen viability (mean $\delta=0.10 \pm 0.13$ ), with equal numbers of lineages showing negative and positive inbreeding depression (Figure 1). However, variation in the effect of the crossing treatment on seed mass was reflected in the large variance in inbreeding depression for seed mass, which ranged from -0.80 to 0.50 (mean $\delta=-0.15 \pm 0.14$; Figure 1).

\section{Multiplicative inbreeding depression}

For the 10 lineages for which we were able to calculate it, multiplicative inbreeding depression varied greatly (ranging from -0.69 to 0.82 ), and the mean multiplicative inbreeding depression value did not differ significantly from zero $(t=0.17 ; \quad P=0.87 ;$ mean $\delta=0.03 \pm 0.17$; Figure 3a). We also calculated multiplicative inbreeding depression for male and female function separately, and these values varied greatly among lineages (Figures $3 \mathrm{~b}$ and c). However, the mean multiplicative inbreeding depression values for both male and female function were close to zero and did not differ significantly from zero $(t=0.10 ; P=0.92$; mean $\delta=0.02 \pm 0.19$ for male function and $t=0.21 ; P=0.84$; mean $\delta=0.04 \pm 0.18$ for female function). 

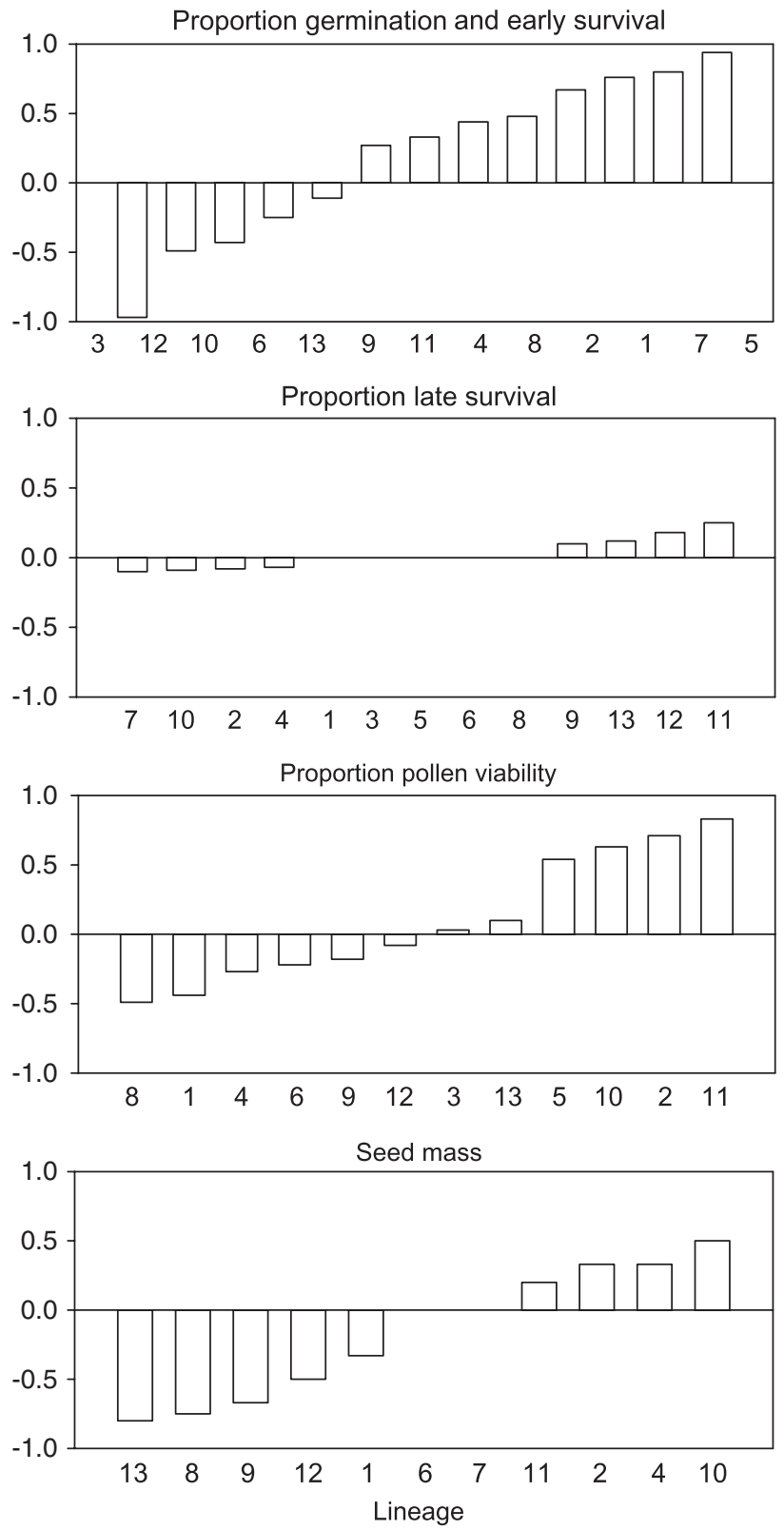

Figure 1 Inbreeding depression for life-history traits of dioecious lineages of $M$. аппиа. Lineages are ordered by increasing inbreeding depression (the lineage numbers refer to the populations from which they are derived and the location of the populations is indicated in Materials and methods).

\section{Discussion}

\section{Low inbreeding depression in dioecious $M$. annua}

Populations that are typically outcrossing are expected to exhibit higher levels of inbreeding depression, on average, than populations that are typically selfing (Husband and Schemske, 1996). As dioecious lineages of $M$. аппиа are obligately outcrossing, we anticipated that inbreeding depression would be substantial in all dioecious $M$. annua lineages. In contrast, we found that inbreeding depression was on average low in the dioecious lineages we sampled. A low inbreeding depression in outcrossing plant populations is uncom-

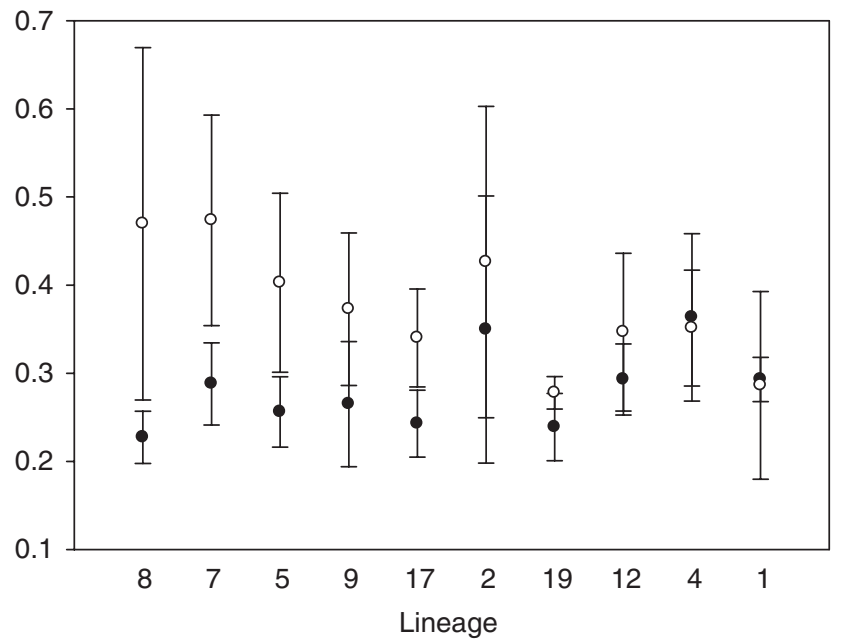

Figure 2 Inbreeding depression for plant biomass of dioecious lineages of M. аnпua. Lineages are ordered by increasing inbreeding depression (the lineage numbers refer to the populations from which they are derived and the location of the populations is indicated in Materials and methods). Closed circles indicate outcrossed offspring and open circles indicate selfed offspring. Error bars are standard errors determined from 10000 replicates from a bootstrap analysis using S-Plus (Insightful Corporation, 2007). For all lineages, selfed and outcrossed progeny did not differ significantly on the basis of bootstrap analysis $(P>0.05)$.

mon but not unprecedented (Bram, 2002; Ægisdóttir et al., 2007). In fact, Amaranthus cannabinus (Amaranthaceae), a dioecious perennial, was found to have surprisingly low inbreeding depression, too (Bram, 2002), similar to that found in the dioecious $M$. аппиа lineages studied here. Bram (2002) suggested that low inbreeding depression in A. cannabinus could have been due to the fact that only early life history traits were measured in this long-lived perennial, plants were not allowed to compete with one another and plants were not grown in the field. In contrast, we measured inbreeding depression in $M$. апnиa under field conditions, allowing for inter- and intra-specific competition, and we accounted for all life-history stages from germination through late survivorship and fertility.

Why should inbreeding depression be so low in this dioecious $M$. апnиa metapopulation? One possible explanation is that range expansion has in fact led to recurrent bouts of biparental inbreeding in the past. It appears that the western European metapopulation of $M$. annua sampled here expanded its range from an eastern Mediterranean refugium after the Pleistocene (Obbard et al., 2006b). As a result, western European populations possess much lower neutral genetic diversity and allelic richness than populations sampled further east (Obbard et al., 2006b). Just as range expansion appears to have caused a reduction in both neutral (Obbard et al., 2006b) and additive genetic diversity for life-history traits (Pujol and Pannell, 2008), it seems plausible that it has led to the purging of deleterious genetic load, or indeed of the fixation of deleterious mutations so that outcrossed and inbred individuals no longer differ in their fitness (Kirkpatrick and Jarne, 2000; Whitlock, 2002). Indeed, in a recent study of inbreeding depression in monoecious populations of $M$. аnnua, B Pujol and JR Pannell (unpublished manuscript) found that populations 

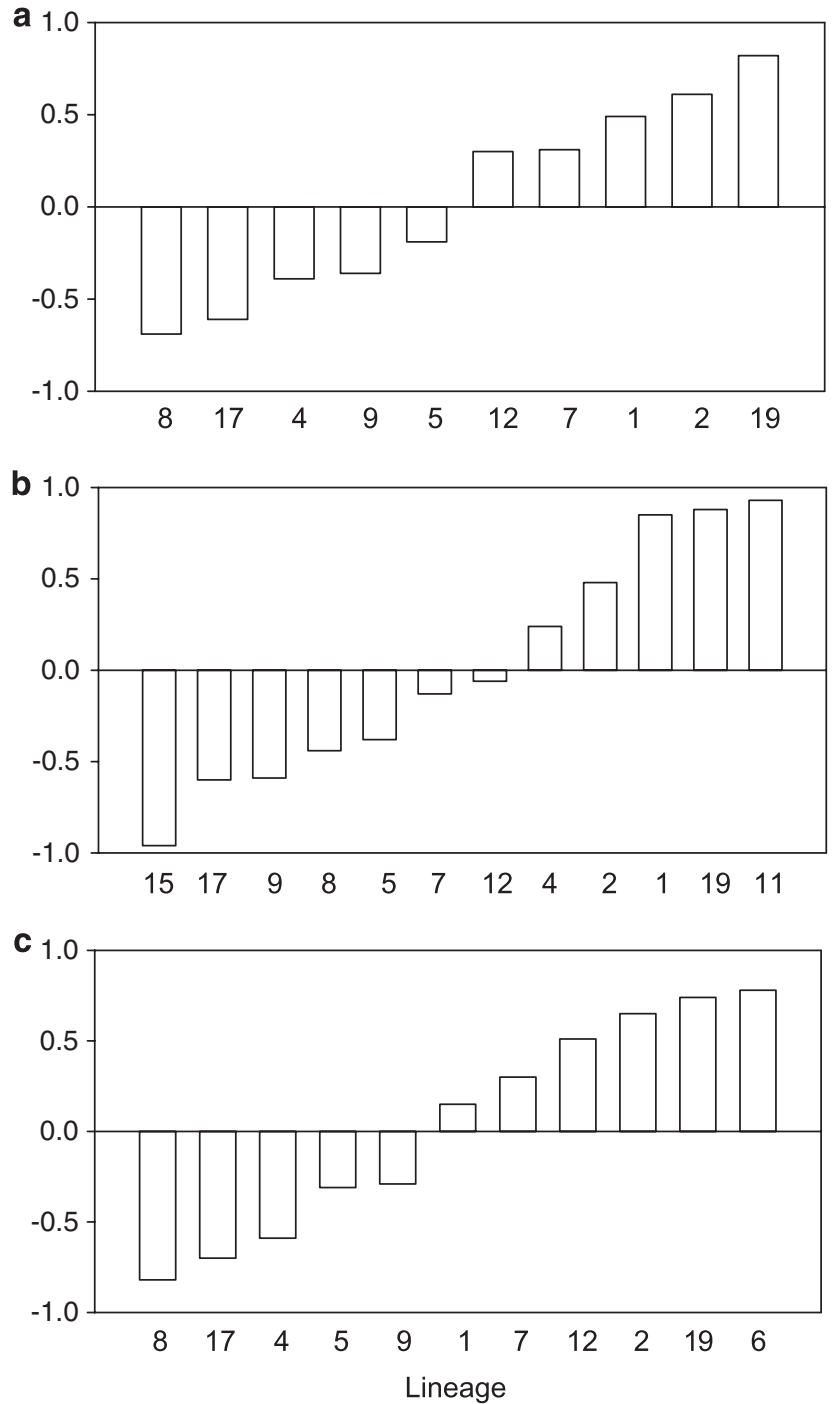

Figure 3 Multiplicative inbreeding depression for dioecious lineages of $M$. annua. Lineages are ordered by increasing inbreeding depression (the lineage numbers refer to the populations from which they are derived and the location of the populations is indicated in Materials and methods). (a) Total multiplicative fitness calculated by finding the product of proportion germination and early survival relative fitness, proportion late survival relative fitness and $0.5 \times$ (seed mass normalized with respect to seed mass in outcrossed progeny) $+0.5 \times$ (proportion viable pollen normalized with respect to proportion viable pollen in outcrossed progeny). (b) Multiplicative male inbreeding depression calculated by finding the product of proportion germination and early survival relative fitness, proportion late survival relative fitness, plant dry mass relative fitness and proportion viable pollen relative fitness. (c) Multiplicative female inbreeding depression calculated by finding the product of proportion germination and early survival relative fitness, proportion late survival relative fitness and seed mass relative fitness.

established by range expansion had lower inbreeding depression than those in the putative refugium. Whether the same process has affected inbreeding depression in dioecious populations of the species complex requires experimental testing.

Our results were characterized not only by a low mean inbreeding depression in dioecious M. annua lineages, but also by a variation in inbreeding depression among lineages, particularly in proportion germination, early survival and seed mass (Table 2). Although range expansion might be able to explain the low average inbreeding depression in $M$. апnиa, it is difficult to see how it could explain the large inter-lineage variation. The result is thus puzzling. One possibility is that variation in inbreeding depression among lineage may the result of strong variation in mutational load (Parker et al., 1995; Schultz and Willis, 1995; Fishman, 2001), for example, of variation among dioecious lineages in the number and type of deleterious recessives and/or overdominant loci that affect fitness. Random accumulation of deleterious mutation can cause a high variance in inbreeding depression without variation in selfing rates (Schultz and Willis, 1995), and this may explain our data. However, it remains difficult to explain both the high variation and low mean in inbreeding depression in terms of a combination of the effects of range expansion and random variation in mutational load.

Another possibility is that the lineages we sampled varied in their levels of recent historical inbreeding. As our experimental design used one selfing replicate per population, it is not possible to determine whether the variance we observed between lineages is actually a measure of variation among lineages or populations in their recent history of inbreeding. M. annua is a ruderal species that exclusively inhabits high-disturbance environments (road banks, building sites and recently disturbed agricultural sites). Although dioecious $M$. апnиa populations are generally large (Eppley and Pannell, 2007b), high-disturbance habitats may result in effective population sizes in some populations that are very much smaller (Husband and Barrett, 1992). In particular, under this scenario, we might expect large differences in the inbreeding effective sizes of populations with different colonization histories. Even though dioecious lineages are obligate outcrossers, in the sense that they cannot self-fertilize, populations recently established by very few individuals will have a small effective size and a recent history of biparental inbreeding, because all individuals will be closely related, whereas biparental inbreeding may be less frequent in populations established by many genotypes, or by older populations that have experienced substantial immigration from other populations.

A surprisingly low inbreeding depression, often with a high variance, has been found for other ruderal outcrossing plant species (Cheptou et al., 2000; Ægisdóttir et al., 2007; Mena-Ali et al., 2008); see Richards (2000) for a counter example. In the case of $M$. annua, metapopulation dynamics following range expansion may explain the extreme pattern of inbreeding depression we see among dioecious populations, as suggested above (B Pujol and JR Pannell, unpublished manuscript). More information is needed about the putative (meta)population dynamics of dioecious $M$. annua populations, and further experiments with replicated lineages within populations would be valuable.

Implications for the maintenance of dioecy in $M$. annua Phylogenetic reconstruction of the genus Mercurialis, and particularly of the clade of annual species in which $M$. annua occurs, indicates that dioecy is ancestral and that monoecy and androdioecy are derived states (Obbard et al., 2006a). There would thus appear to be no hard 
constraint in preventing the breakdown of dioecy in the species under selection for hermaphroditism. The potential for the evolution of hermaphroditism in dioecious populations is even more apparent in the fact that males and females in these populations sometimes produce a few flowers of the opposite gender (Durand, 1963), as is common in many dioecious plant species (Lloyd and Bawa, 1984; Korpelainen, 1998). Under what conditions is our finding of low inbreeding depression in $M$. annua metapopulations consistent with the evolutionary maintenance of dioecy in $M$. annua in the face of such variation?

Wolf and Takebayashi (2004) evaluated the conditions under which hermaphrodites could invade a dioecious population and ultimately replace the males, the females or both genders. They found that dioecious populations would be resistant to hermaphrodite invasion if inbreeding depression was high, unless female seed production was pollen limited. Recent observations and experiments on dioecious $M$. annua populations (E Hesse and JR Pannell, unpublished data) indicate that seed production can be pollen limited at low densities that would occur, for example, during the early generations following population colonization. Thus, even if inbreeding depression were high in $M$. annua, we might expect the evolution of hermaphroditism from dioecy if population densities were frequently low, as might be expected in a colonizing species (see Pannell, 1997a, 2001). Indeed, hermaphroditism tends to occur in M. annua in regions in which population densities are low, whereas populations in dioecious regions are larger and denser (Eppley and Pannell, 2007b).

Of course, it appears from our results here that inbreeding depression in dioecious M. annua is not high. In the case of low inbreeding depression, Wolf and Takebayashi (2004) showed that dioecy should be more vulnerable to the invasion of hermaphrodites. In particular, they predicted that hermaphrodites could invade a dioecious population if

$$
s>\frac{1-o_{h}-p_{h}}{o_{h}(1-2 \delta)},
$$

where $s$ is the prior selfing rate (the proportion of ovules that hermaphrodites self-fertilize before any opportunities for outcrossing), $o_{\mathrm{h}}$ and $p_{\mathrm{h}}$ are the numbers of ovules and pollen grains produced by hermaphrodites relative to females and males, respectively, and is the level of inbreeding depression (modified from equation 7 in Wolf and Takebayashi, 2004). In the case in which there is a linear trade-off between resources invested in male vs female function (that is, the sex-allocation 'fitness set' is linear; Charnov et al., 1976; Charnov, 1982), then $o_{\mathrm{h}}+p_{\mathrm{h}}=1$. In this case, it is clear from Eq. (1) that hermaphrodites will invade a dioecious population as long as the prior selfing rate is greater than zero. It would thus appear that dioecious M. annua populations are potentially very vulnerable to the invasion of hermaphrodites, even in the absence of pollen limitation.

It is likely that the sex-allocation fitness set is not linear in $M$. annua and that $o_{\mathrm{h}}+p_{\mathrm{h}}<1$. Recent results from paternity estimates in $M$. annua indicate that pollen dispersed from a male inflorescence are over $60 \%$ more likely to sire outcrossed progeny than equivalent pollen dispersed from hermaphrodites (Eppley and Pannell, 2007a). Males disperse their pollen from erect peduncles that are held above the plant, whereas hermaphrodites and females release their pollen from subsessile inflorescences in the leaf axils (Durand, 1963; Pannell, 1997c). We might therefore expect that pollen grains dispersed from specialized peduncles have a better chance of reaching stigmas on other plants than those dispersed from the leaf axil (Eckhart, 1999), which the recent study in M. annua confirms (Eppley and Pannell, 2007a). The corollary of this is that hermaphrodites effectively disperse less pollen than they produce, compared with males, so that $o_{\mathrm{p}}$ is smaller than a linear trade-off would predict. The male fitness set is thus probably accelerating rather than linear. We do not know the shape of the female fitness gain curve, but even if it were linear or slightly decelerating, the male fitness set is likely to be sufficient to explain the maintenance of dioecy in $M$. annua in populations in which seed set is not too pollen limited (see Charlesworth and Charlesworth, 1981; Seger and Eckhart, 1996).

Our results here, and the reasoning above, suggest that dioecy is maintained in $M$. annua as a result of the benefits of sexual specialization, particularly by males, rather than by selection to avoid the costs of inbreeding depression. Although it is increasingly accepted that selection for sexual specialization has probably played an important role in the evolution and maintenance of dioecy in plants (reviewed in Charlesworth, 1999; Meagher, 2007), the sexual specialization hypothesis has been rarely explicitly tested (Meagher, 2007). By suggesting that inbreeding depression has probably been relatively unimportant in maintaining dioecy in $M$. annua, our study provides tangential support for the sexual specialization hypothesis. Further experimentation is necessary to estimate levels of inbreeding depression within dioecious populations of $M$. аnnua, both to determine whether the variance we documented occurs primarily among lineages or populations, as well as to compare the expression of inbreeding depression among the different sexual systems displayed by the species complex. Such studies are currently underway.

\section{Acknowledgements}

We thank $M$ Verdú for providing space and facilities for the field experiments in Spain, AM Shaw for help in the field, DJ Obbard and RJA Buggs for help with seed collecting and Benoit Pujol for valuable comments on an earlier draft of this manuscript. Research was supported by grant INT 0202645 from the United States National Science Foundation to SME and grants to JRP from the Natural Environment Research Council, UK.

\section{References}

Ægisdóttir HH, Jespersen D, Kuss P, Stöcklin J (2007). No inbreeding depression in an outcrossing alpine species: the breeding system of Campanula thyrsoides. Flora 202: 218-225.

Ågren J, Schemske DW (1993). Outcrossing rate and inbreeding depression in two annual monoecious herbs, Begonia hirsuta and Begonia semiovata. Evolution 47: 125-135.

Ashman T-L (1992). The relative importance of inbreeding and maternal sex in determining progeny fitness in Sidalcea oregana ssp. spicata, a gynodioecious plant. Evolution 46: $1862-1874$ 
Bram MR (2002). Effects of inbreeding in three populations of the dioecious annual Amaranthus cannabinus. J Torrey Bot Soc 129: $298-310$.

Carr DE, Fenster CB, Dudash MR (1997). The relationship between mating-system characters and inbreeding depression in Mimulus guttatus. Evolution 51: 363-372.

Charlesworth B, Charlesworth D (1978). A model for the evolution of dioecy and gynodioecy. Am Nat 112: 975-997.

Charlesworth B, Charlesworth D (1998). Some evolutionary consequences of deleterious mutations. Genetica 103: 3-19.

Charlesworth D (1999). Theories on the evolution of dioecy. In: Geber MA, Dawson TE, Delph LF (eds). The Evolution of Gender and Sexual Dimorphism in Flowering Plants. SpringerVerlag: Heidelberg. pp 33-56.

Charlesworth D, Charlesworth B (1981). Allocation of resources to male and female functions in hermaphrodites. Biol J Linn Soc 15: 57-74.

Charlesworth D, Charlesworth B (1987). Inbreeding depression and its evolutionary consequences. Annu Rev Ecol Syst 18: 237-268.

Charlesworth D, Charlesworth B (1990). Inbreeding depression with heterozygote advantage and its effect on selection for modifiers changing the outcrossing rate. Evolution 44: 870-888.

Charlesworth D, Morgan MT, Charlesworth B (1990). Inbreeding depression, genetic load and the evolution of outcrossing rates in a multi-locus system with no linkage. Evolution 44: 1469-1489.

Charnov EL (1982). The Theory of Sex Allocation. Princeton University Press: Princeton, USA.

Charnov EL, Maynard Smith J, Bull JJ (1976). Why be an hermaphrodite? Nature 263: 125-126.

Cheptou P-O, Berger A, Blanchard A, Collin C, Escarre J (2000). The effect of drought stress on inbreeding depression in four populations of the Mediterranean outcrossing plant Crepis sancta (Asteraceae). Heredity 85: 294-302.

Christensen R (1990). Log-Linear Models. Springer-Verlag: New York, NY, USA.

Darwin C (1877). The Different Forms of Flowers on Plants of the Same Species. John Murray: London, UK.

Darwin C (1876). The Effects of Cross and Self-fertilization in the Vegetable Kingdom. John Murray: London, UK.

Dorken ME, Friedman J, Barrett SCH (2002). The evolution and maintenance of monoecy and dioecy in Sagittaria latifolia (Alismataceae). Evolution 56: 31-41.

Durand B (1963). Le complexe Mercurialis annua L. s.l.: une étude biosystématique. Ann Sci Nat Bot, Paris 12: 579-736.

Durand B, Durand B (1991). Sex determination and reproductive organ differentiation in Mercurialis. Plant Sci 80: 49-65.

Durand R, Durand B (1992). Dioecy, monoecy, polyploidy and speciation in annual Mercuries. B Soct Bot Fr-Lett 139: 377-399.

Eckhart VM (1992). Resource compensation and the evolution of gynodioecy in Phacelia linearis (Hydrophyllaceae). Evolution 46: 1313-1328.

Eckhart VM (1999). Sexual dimorphism in flowers and inflorescences. In: Geber MA, Dawson TE, Delph LF (eds). Gender and Sexual Dimorphism in Flowering Plants. Springer: Heidelberg.

Eppley SM, Pannell JR (2007a). Density-dependent self-fertilization and male versus hermaphrodite siring success in an androdioecious plant: testing the metapopulation model. Evolution 61: 2349-2359.

Eppley SM, Pannell JR (2007b). Sexual systems and measures of occupancy and abundance in an annual plant: testing the metapopulation model. Am Nat 169: 20-28.

Fisher RA (1949). The Theory of Inbreeding. Oliver and Boyd: London, UK.

Fishman L (2001). Inbreeding depression in two populations of Arenaria uniflora (Caryophyllaceae) with contrasting mating systems. Heredity 86: 184-194.
Frankham R (1995). Inbreeding and extinction: a threshold effect. Conserv Biol 9: 792-799.

Goodwillie C, Kalisz S, Eckert CG (2005). The evolutionary enigma of mixed mating systems in plants: occurrence, theoretical explanations, and empirical evidence. Annu Rev Ecol Evol Syst 36: 47-79.

Husband BC, Barrett SCH (1992). Effective population size and genetic drift in tristylous Eichhornia paniculata (Pontederiaceae). Evolution 46: 1875-1890.

Husband BC, Schemske DW (1996). Evolution of the magnitude and timing of inbreeding depression in plants. Evolution $\mathbf{5 0}$ 54-70.

Insightful Corporation Inc. (2007). S-Plus 8.0. Seattle, WA.

Johnston MO, Schoen DJ (1994). On the measurement of inbreeding depression. Evolution 48: 1735-1741.

Kearns CA, Inouye DW (1993). Techniques for Pollination Biologists. University Press of Colorado: Niwot, CO, USA.

Kirkpatrick M, Jarne P (2000). The effects of a bottleneck on inbreeding depression and the genetic load. Am Nat 155: 154-167.

Koelewijn HP, van Damme JMM (2005). Effects of seed size, inbreeding and maternal sex on offspring fitness in gynodioecious Plantago coronopus. J Ecol 93: 373-383.

Kohn JR, Biardi JE (1995). Outcrossing rates and inferred levels of inbreeding depression in gynodioecious Cucurbita foetidissima (Cucurbitaceae). Heredity 75: 77-83.

Korpelainen H (1998). Labile sex expression in plants. Biol Rev 73: $157-180$.

Lande R (1988). Genetics and demography in biological conservation. Science 241: 1455-1460.

Lande R, Schemske DW (1985). The evolution of self-fertilization and inbreeding depression in plants. I. Genetic models. Evolution 39: 24-40.

Lloyd DG (1975). The maintenance of gynodioecy and androdioecy in angiosperms. Genetica 45: 325-339.

Lloyd DG (1976). The transmission of genes via pollen and ovules in gynodioecious angiosperms. Theor Popul Biol 9: 199-216.

Lloyd DG, Bawa KS (1984). Modification of the gender of seed plants in varying conditions. Evol Biol 17: 255-338.

Lloyd DG, Schoen DJ (1992). Self- and cross-fertilization in plants. I. Functional dimensions. Int J Plant Sci 153: 358-369.

Meagher TR (2007). Linking the evolution of gender variation to floral development. Ann Bot (Lond) 100: 165-176.

Medrano M, Alonso C, Herrera M (2005). Mating system, sex ratio, and persistence of females in the gynodioecious shrub Daphne laureola L. (Thymelaeaceae). Heredity 94: 37-43.

Mena-Ali JI, Keser LH, Stephenson AG (2008). Inbreeding depression in Solanum carolinense (Solanaceae), a species with a plastic self-incompatibility response. BMC Evol Biol 8: 1-10.

Morgan MT (2001). Consequences of life history for inbreeding depression and mating system evolution in plants. Proc Natl Acad Sci USA 268: 1817-1824.

Mutikainen P, Delph LF (1998). Inbreeding depression in gynodioecious Lobelia siphilitica: among-family differences override between-morph differences. Evolution 52: 1572-1582.

Obbard DJ, Harris SA, Buggs RJA, Pannell JR (2006a). Hybridization, polyploidy, and the evolution of sexual systems in Mercurialis (Euphorbiaceae). Evolution 60: 1801-1815.

Obbard DJ, Harris SA, Pannell JR (2006b). Sexual systems and population genetic structure in an annual plant: testing the metapopulation model. Am Nat 167: 354-366.

Pannell J (1997a). The maintenance of gynodioecy and androdioecy in a metapopulation. Evolution 51: 10-20.

Pannell J (1997b). Variation in sex ratios and sex allocation in androdioecious Mercurialis annua. I Ecol 85: 57-69.

Pannell J (1997c). Widespread functional androdioecy in Mercurialis annua L (Euphorbiaceae). Biol I Linn Soc 61 95-116. 
Pannell JR (2001). A hypothesis for the evolution of androdioecy: the joint influence of reproductive assurance and local mate competition in a metapopulation. Evol Ecol 14: 195-211.

Pannell JR, Dorken ME, Pujol B, Berjano R (2008). Gender variation and transitions between sexual systems in Mercurialis annua (Euphorbiaceae). Int J Plant Sci 169: 129-139.

Pannell JR, Obbard DJ, Buggs RJA (2004). Polyploidy and the sexual system: what can we learn from Mercurialis annua? Biol J Linn Soc 82: 547-560.

Parker IM, Nakamura RR, Schemske DW (1995). Reproductive allocation and the fitness consequences of selfing in two sympatric species of Epilobium (Onagraceae) with contrasting mating systems. Am J Bot 82: 1007-1016.

Pujol B, Pannell JR (2008). Reduced responses to selection following species range expansion. Science 321: 96.

Rausch JH, Morgan MT (2005). The effect of self-fertilization, inbreeding depression, and population size on autopolyploid establishment. Evolution 59: 1867-1875.

Richards CM (2000). Inbreeding depression and genetic rescue in a plant metapopulation. Am Nat 155: 383-394.

Sakai AK, Weller SG, Chen M-L, Chou S-Y, Tasanont C (1997). Evolution of gynodioecy and maintenance of females: the role of inbreeding depression, outcrossing rates, and resource allocation in Schieda adamantis (Caryophyllaceae). Evolution 51: 724-736.

SAS Institute (2004). JMP for Windows. Release 5.1. SAS Institute: Cary, NC.

Schultz ST, Ganders FR (1996). Evolution of unisexuality in the hawaiian flora: a test of microevolutionary theory. Evolution 50: 842-855.

Schultz ST, Willis JH (1995). Individual variation in inbreeding, the roles of inbreeding history and mutation. Genetics 141: 1209-1223.

Seger J, Eckhart VM (1996). Evolution of sexual systems and sex allocation in plants when growth and reproduction overlap. Proc $R$ Soc Lond B Biol Sci 263: 833-841.

Stanley RG, Linskens HF (1974). Pollen: Biology, Biochemistry, and Management. Springer Verlag: New York, NY.

Thompson JD, Tarayre M, Gauthier P, Litrico I, Linhart YB (2004). Multiple genetic contributions to plant performance in Thymus vulgaris. I Ecol 92: 45-56.

Whitlock MC (2002). Selection, load and inbreeding depression in a large metapopulation. Genetics 160: 1191-1202.

Wolf DE, Takebayashi N (2004). Pollen limitation and the evolution of androdioecy from dioecy. Am Nat 163: 122-137.

Supplementary Information accompanies the paper on Heredity website (http://www.nature.com/hdy) 